\title{
El campo conceptual TOD/MUERTE en alemán y español: eufemismos y disfemismos
}

\author{
Carmen Mellado BlanCo \\ Universidad de Santiago de Compostela \\ c.mellado@usc.es
}

Recibido: 30 de noviembre de 2012

Aceptado: 10 de enero de 2013

\section{RESUMEN}

En este trabajo se analiza un corpus de unidades idiomáticas plurilexemáticas, tanto lexicalizadas como no, en torno al campo conceptual TOD/MUERTE en alemán y español. En el marco de la lingüística cognitiva se han formulado los modelos cognitivos principales y los tipos de motivación que predominan entre las expresiones del corpus. El objetivo final es determinar qué archimetáforas o metonimias son proclives a la verbalización del tabú de la muerte mediante eufemismos o disfemismos en cada una de las lenguas y describir las simetrías y divergencias encontradas.

Palabras clave: Campo conceptual TOD/MUERTE, metáforas, eufemismos, disfemismos.

\section{Conceptual Field DEATH in German and Spanish: Euphemisms and Dysphemisms}

\begin{abstract}
This paper analyzes a corpus of idiomatic multiword units, both lexicalized and not lexicalized, related to the conceptual field DEATH in German and Spanish. Within the cognitive linguistics framework, here there are formulated the more important cognitive models as well as the types of motivation relying in those expressions. The main objective is to determine which metaphorical schema and metonymical patterns are inclined to verbalize death taboo through euphemisms or dysphemisms in both the languages and describe their convergences and divergences.
\end{abstract}

Keywords: Conceptual Field DEATH, Metaphors, Euphemisms, Dysphemisms.

SUMARIO: 1. Introducción. Elaboración del corpus y objeto de estudio. 2. Eufemismos y disfemismos: caracterización del corpus TOD/MUERTE. 3. Tipos de motivación en los eufemismos y disfemismos del corpus. 3.1. Motivación metafórica: metáforas conceptuales. 3.2. Motivación metafórica basada en marcos of frames. 3.3. Motivación simbólica. 4. Balance final.

\section{Introducción. Elaboración del corpus y objeto de estudio}

En este artículo se presentan los resultados del análisis contrastivo llevado a cabo entre expresiones idiomáticas de las lenguas alemana y española pertenecien- 
tes al campo conceptual TOD/MUERTE ${ }^{1}$. El estudio de la muerte desde un punto de vista lingüístico ha suscitado interés en los últimos años en el seno de la lingüística cognitiva, de manera general en Lakoff/Johnson (1986: 51-52), en Piirainen para el alemán (2002) y para el dialecto del alemán westmünsterländisch (2000), en Anders (1995) para el inglés, en Marín-Arrese (1996) para el inglés y el español, en Bierich (1998) para el checo, ruso, croata y serbio y en Buján Otero (2012) para el alemán y el gallego. Para el alemán y el español, contamos con los estudios contrastivos de Piñel López (2003), Buján Otero / Mellado Blanco (2010) y Mellado Blanco / Iglesias Iglesias (2011), estando los dos últimos centrados en aspectos contrastivos de tipo pragmático basados en lingüística de corpus. La vertiente eufemística de las expresiones del campo conceptual MUERTE se aborda en Luchtenberg (1985: 95-102) y en Hessky (2001) en relación al alemán, para el francés y el italiano en Reutner (2009: 45-52), para el español en Crespo Fernández (2008), estudios todos ellos muy valiosos porque suponen un acercamiento pragmático al tema. Un enfoque especialmente original es el de Baranov y Dobrovol'skij (2009: 453-459), quienes relacionan la forma interna (imagen) de los fraseologismos (FR) que designan 'muerte' con la posibilidad de desarrollar polisemia regular en su significado y con posibles restricciones y preferencias de uso.

Las unidades estudiadas en este trabajo proceden de diccionarios idiomáticos monolingües y bilingües, del corpus FRASESPAL, así como del listado de expresiones alemanas, algunas de ellas no lexicalizadas, recogidas en Piirainen (2002) a través de encuestas ${ }^{2}$, algunas de ellas tampoco lexicalizadas. Entre los fraseologismos (FR) no se han considerado ni las colocaciones, del tipo al. unerwartet sterben/esp. morir repentinamente, por su falta de idiomaticidad, ni tampoco paremias ni fórmulas rutinarias, por rebasar el límite suboracional en su estructura. Requisito imprescindible es, asimismo, el carácter plurilexemático de las expresiones, por lo que no se contabilizan los numerosos verbos prefijados del alemán con el significado 'morir' (cfr. los verbos recogidos en Bielińska, 2002) ${ }^{3}$. Las expresiones recogidas en el corpus global se caracterizan por un registro estilístico coloquial, diferentes marcas diatópicas y un desigual grado de lexicalización.

Por último resaltar la enorme ayuda que ha supuesto para el presente trabajo la elaboración del diccionario de 35.000 FR Idiomatik Deutsch-Spanisch (Schemann et al. 2013) en el seno del proyecto FRASESPAL, puesto que hemos podido in-

${ }^{1}$ Datos del proyecto interuniversitario del Ministerio de Ciencia e Innovación (HUM200762198/FILO) La estructura idiomática del alemán y el español. Un estudio cognitivo a partir de un corpus onomasiológico, dirigido por mí desde la Universidad de Santiago de Compostela.

${ }^{2}$ Agradezco la contribución de Juan Pablo Larreta, miembro de FRASESPAL, por la elaboración de una parte del corpus de unidades del español mediante encuestas a informantes. Algunas de las expresiones recogidas no están lematizadas en ninguno de los diccionarios consultados.

${ }^{3}$ Interesante es en todo caso, desde un punto de vista cognitivo, que los prefijos más frecuentes en estos verbos encajan en su semántica con las metáforas estudiadas en el presente trabajo. El prefijo "ab-" "die Fortbewegung von etwas weg" (abreisen, abfahren, abtreten), el prefijo "ent-" "die inchoative Aktionsart" (entschlafen, entschlummern), el prefijo "um-" indica "das Überführen von der vertikalen in die horizontale Lage" (umkippen, umkommen), etc. (BIELIŃSKA 2002: 204-206). 
corporar el material idiomático alemán en el corpus con todas las equivalencias posibles al español. En un cómputo general, el grueso de expresiones idiomáticas del campo conceptual TOD/MUERTE con el que hemos trabajado, y del que hemos seleccionado las expresiones referidas a 'morir' y 'estar muerto', asciende en su totalidad en alemán a 480 y en español a 373 unidades. El objetivo del análisis contrastivo llevado a cabo ha sido comparar cuantitativa y cualitativamente el uso de eufemismos y disfemismos en el campo cognitivo TOD/MUERTE. Para ello, se ha procedido a analizar las modelos cognitivos y las archimetáforas que emplea cada idioma para expresar el fenómeno de la muerte, prestando especial atención a los mecanismos de motivación de las unidades seleccionadas (cfr. Burger 2010: 87-107; Iñesta/Pamies 2002). Para la formulación de las archimetáforas nos ha sido de gran utilidad la clasificación onomasiológica del corpus del proyecto FRASESPAL (Mansilla Pérez 2010), organizada en diez grandes taxones, algunos de ellos a su vez subclasificados de acuerdo con la invariable semántica del significado fraseológico de las entradas ${ }^{4}$. Los taxones constituyen criterios antropológicamente relevantes que definen de algún modo la relación del ser humano con la muerte como proceso ('proximidad de la muerte'/ 'morir') y como estado ('estar ya muerto') y han sido formulados mediante una metodología inductiva. A este respecto hay que anotar que, en general, las expresiones relativas a la 'muerte' como estado son significativamente más reducidas que las relacionadas con el proceso dinámico de 'morir', como constata Anders (1995: 60) en su trabajo, ya que "[d]as Sterben wird als dynamischer Vorgang interpretiert, der Tod als abstrakter Zustand" y en el primer caso "mehr Gesichtspunkte vorhanden sind, die beschrieben werden können".

La formulación de los modelos cognitivos idealizados ${ }^{5}$ y las archimetáforas ofrecen en el marco de la lingüística cognitiva una valiosa plataforma para conocer los mecanismos de conceptualización que utiliza el ser humano para denominar a la muerte y al trance de morir. En este trabajo, basado en los subcampos M.5.

${ }^{4}$ La clasificación seguida en el corpus es la siguiente: M.1. Expresiones para designar la muerte como agente. M.2. Expresiones para designar "cadáver". M.3. Agonizar. M.4. Estar a punto de morir. M.5. Morir (M.5.1. Expresiones para morir en general. M.5.2. Morir a consecuencia de una acción deliberada, morir en una empresa, por un ideal, etc. M.5.3. Morir de muerte natural. M.5.4. Morir asesinado. M.5.5. Morir por un accidente. M.5.6. Morir violentamente. M.5.7. Morir apaciblemente. M.5.8. Morir joven. M.5.9. Morir de repente. M.5.10. Morir lúcidamente. M.5.11. Morir solo y abandonado. M.5.12. Morir por suicidio). M.6. Enterrar, entierro, luto. M.7. Estar ya muerto. M.8. Librarse de la muerte. M.9. Permitir a alg. que siga viviendo. M.10. Asesinato, asesinar. En otros corpus como el de BIERICH (1998) se ofrece una clasificación semántica procedural de las expresiones en consonancia con el proceso natural de la muerte. En el diccionario onomasiológico de SCHEMANN (2012: 35-38) se ofrece igualmente una clasificación temática con los siguientes subapartados: $\mathrm{Ba} 1$ Geburt, $\mathrm{Ba} 2$ sterben (müssen), $\mathrm{Ba} 3$ sich töten, $\mathrm{Ba} 4$ töten, $\mathrm{Ba} 5$ tot, $\mathrm{Ba} 6$ noch lebendig, $\mathrm{Ba} 7$ Beerdigung, Trauer.

5 Entendemos el concepto de "modelo cognitivo idealizado" en el sentido de JÄKEL (2003: 140), como conjunto de metáforas o archimetáforas conceptuales que responden a un mismo patrón cognitivo en la relación expresada entre sus respectivos dominios fuente y meta (vid. también MeLLADO BLANCO 2013). 
(excepto M.5.12.), M.6. y M.7. (vid. nota 4) del corpus FRASESPAL, restringimos el análisis a los siguientes modelos cognitivos de base metonímica MORIR ES DEJAR DE HACER UNA ACTIVIDAD COTIDIANA y MORIR ES EXPERIMENTAR UNA REACCIÓN CORPORAL, a algunas archimetáforas como MORIR ES DESCANSAR y a las expresiones en torno al frame ENTERRAMIENTO. Hemos elegido los mencionados modelos y archimetáforas por ser buenos representantes de disfemismos y de eufemismos, y al mismo tiempo por ofrecer interesantes diferencias interlingüísticas sobre todo en cuanto a la productividad de los disfemismos.

De acuerdo con Lakoff/Johnson (1986: 39), en este trabajo se defiende que la metáfora no solo impregna el lenguaje en todas sus dimensiones, sino también el pensamiento y la acción, puesto que "nuestro sistema conceptual ordinario, en términos del cual pensamos y actuamos, es fundamentalmente de naturaleza metafórica". El mecanismo asociativo de la metáfora es el que explica el nacimiento espontáneo de nuevos disfemismos basados en modelos cognitivos preexistentes que son parte constituyente del lexicón mental de los hablantes de una lengua. Así, el modelo cognitivo MORIR ES DEJAR DE REALIZAR UNA ACTIVIDAD COTIDIANA ha generado, en consonancia con su gran productividad en alemán, los neologismos: er hat die/seine Zeitung abbestellt; er hat die FAZ/das Handelblatt/den Heideboten/das Neue Deutschland abbestellt, etc. Estas expresiones se apoyan en un sistema conceptual metafórico preexistente que explota un esquema común de pensamiento basado en que una persona que ha muerto deja de realizar las actividades de la vida cotidiana, ya sean vitales como comer, hablar o respirar, o bien sociales, como comprar o leer el periódico.

En el campo conceptual TOD/MUERTE advertimos de manera ejemplar cómo el hombre se sirve de lo más cercano: su experiencia con las reacciones corporales que provoca la muerte, tanto en seres humanos como en animales, para denotar el referente de la muerte (vid. infra modelo cognitivo MORIR ES EXPERIMENTAR UNA REACCIÓN CORPORAL).

\section{Eufemismos y disfemismos: caracterización del corpus TOD/MUERTE}

Tanto eufemismos como disfemismos son frecuentes en el campo conceptual de la muerte por el miedo atávico que ésta provoca en el ser humano durante toda su vida. Es un campo donde predomina el tabú ya desde las culturas primitivas (Piñel 2003: 229), lo cual hace que las expresiones a las que aluden se revistan de un "manto" eufemístico o disfemístico para no hacer referencia al objeto denotado directamente (Hessky 2001: 171). En un plano estrictamente lingüístico, lo primero que llama la atención es que tanto eufemismos como disfemismos evitan que se pronuncie el ortofemismo ${ }^{6}$ morir/sterben o muerto/tot.

\footnotetext{
${ }^{6}$ Según CRESPO FERNÁNDEZ (2008: 98), el ortofemismo es "el término axiológicamente neutro o estrictamente referencial del concepto tabú, como es el caso de la palabra muerte".
} 
Conforme a Jachnow (1994) y Piirainen (2002: 217), los mecanismos psicopragmáticos para designar veladamente a la 'muerte' son la glorificación mediante la religión, su minimización, dulcificación o cuasi-negación (eufemismos), y por otra parte su banalización, ridiculización o brutalización, mediante la acentuación de su carácter cotidiano.

Algunos de los eufemismos, en su búsqueda por "dulcificar la realidad", niegan la muerte apoyándose en el mito de la vida eterna, el cual sirve de consuelo para encarar el final de la vida. En palabras de Fructuoso (2006), "[1]a muerte es lo definitivamente inexplicable. Tan incomprensible, tan terrible en su insondable misterio que casi sólo puede ser pensada a través del recurso al mito. El alma será el mito, el cristal a través del cual resultará soportable pensar la muerte”. A su vez, Profantová (2006: 300), destaca el valor de las creencias religiosas de los pueblos como estrategia importante de superación de la muerte: "[d]ie Überwindung des Todes durch emotional-rationale Mittel der verschiedenen Religionen und den Glauben an ein Leben nach dem Tod". Teniendo esto en cuenta, es fácil comprender cómo muchas metáforas basadas en el eufemismo tienen al alma como protagonista y su liberación del cuerpo (den Geist aufgeben) en el momento de la exhalación del último aliento (die/seine Seele aushauchen; sein Leben aushauchen; seinen Atem aushauchen). La inmortalidad del alma supone para ésta disfrutar de la compañía divina (jmds. Seele ist (schon) bei Gott). Por su parte, al contrastar las imágenes que dan cuerpo a las estrategias aludidas, se visualizan caminos convergentes y divergentes que cada lengua ha ido adoptando en su evolución con respecto a los eufemismos y disfemismos del campo cognitivo TOD/MUERTE. Los dominios fuente de los que beben los eufemismos y disfemismos conceptualizan diferentes maneras de enfrentarse con el tabú de la muerte desde distintas perspectivas. Como muy acertadamente afirma Crespo Fernández (2008: 85):

[L]a estructura cognitiva del dominio fuente permite categorizar el dominio término a partir de nuestra propia experiencia física o cultural, no es sino en esta correspondencia entre ambos dominios conceptuales donde la asociación cognitiva lleva a cabo la atenuación y, dependiendo del dominio fuente empleado en la categorización eufemística, estaremos conceptualizando el tabú de una u otra manera. El dominio fuente es, por tanto, utilizado para entender, estructurar y, en casos como el propuesto, mitigar la referencia al hecho de la muerte.

Si partimos de la definición que da el diccionario de Glück (1993: 176), un eufemismo "ist eine durch gesellschaftliche, ideologische oder religiöse Konventionen verursachte beschönigende, 'verhüllende' Ausdrucksweise". A su vez, el DRAE define el eufemismo como "manifestación suave o decorosa de ideas cuya recta y franca expresión sería dura o malsonante", y el disfemismo como "modo de decir que consiste en nombrar una realidad con una expresión peyorativa o con intención de rebajarla de categoría, en oposición a eufemismo" (cfr. también 
Piirainen 2002: 217). Más completa nos parece la definición de eufemismo y disfemismo de Anders (1995: 33)

Der Euphemismus verschleiert den Ausdruck, den es zu vermeiden gilt und fungiert dabei gleichzeitig als Spiegel gesellschaftlicher Anschauungen. Stilistisch gehört er meist einem gehobenen Sprachregister an. Im Gegensatz zum Euphemismus steht der Disphemismus - in humorvollen, groben oder obszonen Bildern wird Ernstes oder Erhabenes ins Lacherliche gezogen. Diese scherzhaften Ersatzbezeichnungen gehören meist den unteren Sprachregistern, oft auch dem Slang, an.

Los disfemismos, aun teniendo como referente último la misma realidad que los eufemismos, a saber, el fenómeno tabuizado de la muerte, aluden a dicha realidad en un tono humorístico, lo cual provoca automáticamente una distancia con respecto al suceso, relativizando su importancia (Piirainen 2002: 217). Las expresiones basadas en el disfemismo son al mismo tiempo irónicas porque ridiculizan al referente y ponen en entredicho su importancia. Asimismo, estas expresiones están dotadas de un alto grado de ingenio, lo cual acentúa su efecto hilarante en el oyente. Por lo que respecta al nivel de uso, mientras que el eufemismo del campo conceptual TOD/MUERTE suele emplearse en un ámbito culto, como por ejemplo el eclesiástico, el disfemismo va, generalmente, acompañado de la marca 'coloquial', 'informal' o 'vulgar'.

Este es el motivo por el cual eufemismos y disfemismos con el significado 'morir' no son intercambiables entre sí en el contexto, como apunta Penadés Martínez (2012: 260-261) en relación a los disfemismos cascarla, espicharla, espicharlas, hincarla, palmarla, chingarla; diñarla; endiñarla; espelecharla, y a los eufemismos dar el/su alma a Dios, descansar en la paz del Señor, llamar a alg. el Señor, etc. Los eufemismos por una parte y los disfemismos por otra estarían, según Penadés Martínez (2012: 260), en "distribución complementaria por su marcación de estilo, que conduce a utilizarlas en contextos de naturaleza diferente" ${ }^{8}$. Teniendo en cuenta la teoría de los actos de habla (cfr. Searle 1969), la función primera de los disfemismos sería la expresiva humorística y las implicaturas principales del hablante serían las de la IRONIZAR o BANALIZAR, p. ej. esp. fiambre para 'muerto' y esp. pijama de palo/al. Holzpyjama para 'ataúd'.

\footnotetext{
${ }^{7}$ En esta definición falta, no obstante, la mención del papel colaborador del oyente para que el eufemismo tenga lugar. Chamizo Rodríguez (2004: 46) sostiene que "cuando el oyente no es cooperativo (o no quiere serlo) desaparece el efecto eufemístico de las proferencias". A este respecto también comenta JACHNOW (1994: 180-181), "[d]ie Untersuchung des Euphemismus kann ohne die Einbeziehung der Hörerseite aber niemals vollständig sein".

${ }^{8}$ Ya el lexicógrafo CASARES (1950: 153) se refirió a los eufemismos como fórmulas literarias de la lengua escrita y a los disfemismos como expresiones "plebeyas": "[...] podemos colocar sobre el tapete las fórmulas siguientes, estilísticamente graduadas, partiendo de las que son propias de la elocución literaria o de la lengua escrita, hasta llegar a las francamente plebeyas: finar, expirar, fallecer, acabar, pasar a mejor vida, espichar, palmar, hincar el pico, estirar la pata. ¿Cuál es el substrato conceptual irreductible y común a todas estas fórmulas? Morir".
} 
Existen determinados dominios fuente propensos a ser conceptualizados por medio de un disfemismo, como las expresiones que significan 'haber muerto' desde la perspectiva de las actividades corporales o intelectuales que el ser humano deja de realizar cuando muere (p. ej. esp. colgar los tenis; no contarla / al. den Löffel abgeben; keinen Piep mehr sagen) o desde el ángulo de las reacciones corporales al morir: esp. quedarse tieso (en relación al rigor mortis), estirar la pata, torcer la pestaña, torcer el pescuezo, poner los ojos en blanco / al. den Arsch zukneifen, alle viere von sich strecken; die Augen auf Null stellen, etc. Se trata en todos los casos citados de metonimias basadas en una relación de contigüidad causaefecto, en los que la imagen hace alusión al efecto inmediato que produce la muerte en el ser humano o animal. En otras ocasiones, los disfemismos no descansan en metonimias, sino en metáforas. Así, la metáfora MORIR ES MARCHARSE es muy productiva a la hora de generar disfemismos de tono humorístico que se usan normalmente en tiempo verbal pasado: esp. irse al otro barrio; liar el petate; ahuecar el ala / al. ein Stockwerk/eine Etage tiefer ziehen; sein Ränzlein schnüren.

Tanto en español como en alemán se observa un fuerte proceso de arcaización de eufemismos procedentes del ámbito religioso y relacionados con la idea del paso del alma a otro mundo o de la eternidad del alma ${ }^{9}$. Dichos eufemismos han dejado de tener como referente principal el acto de morir, desarrollando significados por un procedimiento de polisemia regular (Baranov/Dobrovol'skij 2009: 453459; Mellado Blanco / Iglesias Iglesias 2011: 123-126). Tal es el caso de FR como al. den Geist aufgeben; den Weg alles Irdischen gehen; den Schlaf der Gerechten schlafen ${ }^{10}$ / esp. pasar a mejor vida; descansar/dormir el sueño de los justos, entre otros muchos, los cuales han pasado de un nivel elevado formal a uno coloquial adoptando nuevos significados a partir de 'morir', en muchos casos con sujeto [-hum] referentes a procesos de la vida moderna como 'avería' de ordenadores, electrodomésticos o vehículos. En el siguiente testimonio, el FR den Weg alles Irdischen gehen ha adoptado el significado de 'desaparecer' con un sujeto [-hum]:

(1) Nicht viel hat gefehlt, und die historische Papiermaschine PM1 wäre den Weg alles Irdischen, in die Verschrottung gegangen. (A98/SEP.53617 St. Galler Tagblatt, 01.09.1998, Ressort: TB-GO) [Beleg aus COSMAS II].

La generalización de un uso irónico aplicado a sujetos [-hum] lleva a que cuando estas expresiones se utilizan con el sentido originario 'morir', con sujeto [+hum], se haga en tono humorístico o disfemístico, como se aprecia en el siguiente ejemplo periodístico con el FR pasar a mejor vida:

(2) Ataúd ecológico para pasar a mejor vida con la conciencia ecológica tranquila. $<$ www.es.euronews.net/tag/muerte>

\footnotetext{
${ }^{9}$ Cfr. a este respecto SCHEMANN (2012: 15-16) en relación a la arcaización de las expresiones religiosas del subcampo semántico 'suicidio', así como BuJÁn OTERO (2012).

${ }^{10}$ Para un estudio pragmático detallado del al. den Schlaf der Gerechten schlafen y esp. descansar/dormir el sueño de los justos vid. BujÁn Otero / MELlado BlANCO (2010).
} 
Podríamos estar ante FR con doble vertiente funcional, dependiendo de la situación de uso y de la intencionalidad del hablante. En el primer caso (uso disfemístico) se presenta una metaforización por cambio clasemático cuando el sujeto [+hum] pasa a ser sujeto [- hum] (ejemplo 1), o simplemente un cambio en el registro cuando el sujeto sigue con el rasgo semántico [+hum] (ejemplo 2). La trivialización de las expresiones eufemísticas hace que se conviertan en disfemísticas, lo cual conlleva un cambio de registro en el nivel estilístico, pasando de culto, literario, formal o elevado a coloquial, con intencionalidad humorística o irónica, según los contextos. Ruiz Gurillo (2009: 376) comenta en este sentido que "el cambio de registro es, en el nivel sincrónico, un indicador de ironía", fenómeno que parece ajustarse a nuestros casos de estudio.

Por los ejemplos estudiados en el corpus FRASESPAL, se registra un importante retroceso de uso de eufemismos relacionados directamente con el ámbito religioso en alemán y español. En el caso de emplearse lo hacen a menudo o bien en un sentido translaticio (vid. ejemplo 1), o bien en tono disfemístico (vid. ejemplo 2). En este contexto, contamos para el español con el interesante estudio empírico realizado por Crespo Fernández (2008) a partir de 1253 inscripciones en nichos y losas desde 1878 hasta nuestros días, el cual pone de manifiesto un claro retroceso de los eufemismos basados en metáforas que "constituyen un recurso propio del sentimentalismo propio de épocas pasadas y poco común de la sociedad actual". Con ello se refiere en concreto a los epitafios basados en las metáforas MORIR ES SUBIR AL CIELO y MORIR ES CAER POR DIOS Y POR ESPAÑA (asociada a los caídos en la Guerra Civil Española). Asimismo, la metáfora MORIR ES DESCANSAR se ha reducido hoy a un cuarto desde las primeras inscripciones estudiadas a partir del s. XIX.

\section{Tipos de motivación en los eufemismos y disfemismos del corpus}

De acuerdo con la clasificación de la motivación realizada por Dobrovol'skij/Piirainen (2009), nos centraremos en la motivación metafórica (metáforas conceptuales y metonimias por una parte y metáforas basadas en marcos, frames, por otra parte) y en la motivación simbólica, de raíces culturales como la Antigüedad Clásica, la literatura universal o la Biblia.

\subsection{Motivación metafórica: metáforas conceptuales}

A) Motivación metafórica la encontramos por ejemplo en las siguientes metáforas conceptuales:

1. MORIR ES TENER POCO TIEMPO, con los eufemismos: esp. llegarle a alg. la/su hora; tener los días contados; tener las horas contadas; acabar su tiempo; al. jmds. Tage/Stunden sind gezählt; jmds. Zeit/Stunde ist gekommen; jmds. letzte Stunde hat geschlagen; das letzte Stündlein hat geschlagen/kommt; jmds. Uhr/Sanduhr ist abgelaufen; jmds. Uhr hat geschlagen/ist stehen geblieben. 
2. MORIR ES DESCANSAR ${ }^{11}$, ya presente en la Antigüedad (Piñel 2003: 233) en forma de eufemismos ${ }^{12}$. Así en español: descansar en paz; descansar en la gloria eterna; descansar/reposar en la paz del Señor; descansar/dormir el sueño de los justos; descansar en tierra santa; descansar/reposar junto al Señor; descansar en tierra extraña; dormir el sueño eterno. En alemán: in den ewigen Frieden eingehen; zur ewigen Ruhe eingehen; seine ewige Ruhe/seinen Frieden finden; für immer eingeschlafen sein; den Schlaf der Gerechten schlafen; für immer zur Ruhe gehen; sich zur letzten Ruhe betten; in ewigem Frieden ruhen; in fremder Erde ruhen; in Gottes Erdboden ruhen; in Gott ruhen; den ewigen/letzten Schlaf schlafen. Para algunos autores (Chamizo Domínguez / Sánchez Benedito 2000: 77), la metáfora MORIR ES DESCANSAR está estrechamente ligada e incluso motivada en la metáfora LA MUERTE ES UN VIAJE, ya que el final del viaje supone un descanso para el viajero.

3. MORIR ES APAGARSE UNA LUZ ${ }^{13}$, representada tanto mediante eufemismos (en español apagársele a alg. la luz de la vida; apagarse la vida de alg.; cerrar los ojos a la luz del mundo; en alemán: jmds. Lebenslicht ist abgebrannt/verloschen; jmds. Lebenslicht wurde ausgeblasen; jmdm. ist das Licht ausgegangen), como por medio de disfemismos (en español: apagársele/acabársele a alg. la candela; en alemán: das Lämpchen auspusten; das Licht ausknipsen).

4. MORIR ES VIAJAR, metáfora que se encuadra en el "esquema de imagen" CAMINO. Los esquemas de imagen son modelos recurrentes y dinámicos de nuestra experiencia corporal preconceptual y sensomotora, los cuales, por este motivo, son buenos candidatos a ser universales cognitivos y a servir de base de metáforas conceptuales y orientacionales (vid. Lakoff 1987: 267) ${ }^{14}$. Un esquema de imagen importante en el campo conceptual TOD/MUERTE es el del CAMINO, que da pie a un elevado número de archimetáforas, muchas de ellas mixturadas con un componente simbólico-religioso (vid. infra apartado 3.3.). Algunas de las archimetáforas, representadas por un elevado número de expresiones metafóricas,

${ }^{11}$ Ya en la Ilíada, Homero llama a la muerte el "hermano gemelo del sueño" (vid. BIERICH 1998: 21). CRESPO FERNÁNDEZ (2008) muestra en su estudio empírico que, a pesar de haber decrecido en las últimas décadas, la metáfora MORIR ES DESCANSAR es la más frecuente en los epitafios de las tumbas. Se trataría de un eufemismo en el que la muerte se presenta como una liberación de este mundo hacia una vida exenta de agitación y sufrimiento (PIIRAINEN 2002: 226).

${ }^{12}$ En alemán se encuentra también el disfemismo ein Nickerchen in der Kiste machen. Con esta metáfora se registran los monolexemas en español descansar y reposar; en alemán los verbos prefijados einschlafen, entschafen, entschlummern y einschlummern (BIELIŃSKA 2002: 205).

${ }^{13}$ En estos FR se identifica la luz con la vida, los FR con luz/Licht ponen de manifiesto la dualidad "vida-luz" vs. "muerte-sombra", en la que se apoyan también otras expresiones metafóricas relativas al mundo de las tinieblas (muerte), en consonancia con el imaginario ya presente en la Biblia y Antigüedad Clásica.

${ }^{14}$ De acuerdo con la teoría cognitiva de LAKOFF (1987: 267), los "image schemata" son "relatively simple structures that constatly recur in our everyday bodily experience: CONTAINERS, PATHS, LINKS, FORCES, BALANCE, and in various orientations and relations: UP-DOWN, FRONT-BACK, PART-WHOLE, CENTER-PERIPHERY". 
tanto lexicalizadas como no, $\operatorname{son}^{15}$ : LA VIDA ES UN CAMINO; VIVIR ES ANDAR UN CAMINO; LA PERSONA QUE VIVE ES EL VIAJERO; MORIR PRONTO ES ACERCARSE AL FINAL DE UN CAMINO; MORIR ES FINALIZAR UN CAMINO; MORIR ES SALIR DE CASA ${ }^{16}$; MORIR ES DESPEDIRSE $^{17}$; MORIR ES ATRAVESAR UN UMBRAL; MORIR ES MARCHARSE/EMPRENDER UN VIAJE ${ }^{18}$.

Según Schemann (2012: 20), en la archimetáfora MORIR ES VIAJAR, la muerte se concibe en sentido amplio como "Übergang von einer 'Lebensform' in eine andere", tratándose según su estudio de la metáfora más productiva dentro del campo conceptual TOD. Algunos autores (Bultnick 1998: 34-38) consideran esta metáfora como una variante de la archimetáfora más general MUERTE ES MOVIMIENTO, que relaciona directamente el cambio de estado de vivo a muerto con el de moverse físicamente del lugar de donde se estaba hacia otro lado (p. ej. esp. irse al otro barrio / al. ans andere Ufer gehen). Dentro del esquema del CAMINO, nos centramos en la archimetáfora MORIR ES MARCHARSE/EMPRENDER UN VIAJE, en el que abundan los disfemismos. En alemán: sein Ränzlein schnüren; die Reisestiefel anziehen; die Fahrkarte lochen; den (großen) Abflug machen; die ganz große Flatter machen; die Flatts machen; die Flocke machen; den Flattermann machen; die große Fliege machen; die Kratze machen; die Mücke machen. En español: liar el petate; estar listo de papeles; ponerse el traje definitivo; tener listos los papeles; estar listo; irse al otro barrio; ahuecar el ala. Como eufemismos en alemán registramos: auf die große Reise gegangen sein; sich auf eine lange Reise begeben; auf eine lange Reise gehen müssen; den Weg gehen, den wir alle gehen müssen. En español: abandonar/dejar este mundo; salir/irse de este mundo. En algunos eufemismos de esta archimetáfora se observa hoy (vid. supra) un uso disfemístico (al. den Weg allen Fleisches/alles Irdischen gehen/ esp. irse al otro mundo).

En algunos casos queda patente que se trata de un viaje que se hace por última vez y de manera definitiva, lo cual se expresa normalmente por eufemismos (en alemán: den letzten Weg gehen; seinen letzten Gang tun; die letzte Fahrt machen; die letzte Reise/Fahrt antreten (müssen); sich auf seine letzte Reise machen; den letzten Zug nehmen; seine letzte Heimstatt finden; en español: marcharse/irse para siempre; hacer/emprender el último viaje; partir hacia el/su último viaje; encontrar la/última morada; el viaje sin retorno), y en menor medida por disfemismos

${ }^{15}$ De este conjunto de archimetáforas se desprende que el hombre es un viajero que vive mientras recorre un camino, al final del cual, al morir, se despide y lo despiden, traspasando un umbral y empezando después de este umbral un nuevo camino que es una nueva vida.

${ }^{16}$ En alemán: das Haus verlassen; die Tür hinter sich zumachen.

${ }^{17}$ En español: decir adiós a este mundo; despedirse del/de este mundo; despedir el alma; decir adiós a este valle de lágrimas; darle el último adiós a alg. En alemán: Abschied nehmen; den großen Abschied machen; das letzte Lebewohl sagen; der Welt ade/adieu sagen; dem Boandlkramer Grüß Gott sagen.

${ }^{18}$ En algunos casos se focaliza la perspectiva de los que se quedan, como en los FR esp. alg. nos ha dejado (para siempre), alg. ya no está entre nosotros / al. (für immer) von uns gegangen sein. 
(en alemán: weg ohne Rückfahrkarte sein; die Biege für immer machen; den großen Abgang für immer machen).

Con respecto a la metonimia, hay que señalar que se encuentra muy representada en el corpus, en especial en los dos siguientes modelos cognitivos basados en la relación de contigüidad metonímica de causa-efecto. En la totalidad de los subapartados de ambos modelos predominan los disfemismos:

1. MORIR ES DEJAR DE HACER UNA ACTIVIDAD COTIDIANA

1.1. MORIR ES DEJAR DE HABLAR / MORIR ES CALLAR. En alemán: nicht mehr reden können; den letzten Piep sagen; keinen Piep/Ton mehr sagen; nicht mehr zip noch zap sagen; keinen Laut von sich geben; keinen Mucks mehr machen; jmd. schweigt jetzt für immer; auf ewig verstummt sein; zum ewigen Schweiger mutiert sein; jmd. ist jetzt bumsstill. En español: no contarla/contarlo; callar para siempre; cerrar el hocico; no decir ya ni mu; estar cerca del cortijo de los "callaitos" ${ }^{\text {"1 }}$; hacer mutis por el foro ${ }^{20}$. Como eufemismo: esp. no vivir para contarlo.

1.2. MORIR ES DEJAR DE COMER. En alemán: das letzte Brötchen sein letztes Stück Brot gegessen haben; seine/die letzten Essensmarke abgegeben haben; keine Essensmarke mehr brauchen. En español: doblar la servilleta; entregar la cuchara.

1.3. MORIR ES PRESCINDIR DEL CALZADO. En alemán: die Schuhe stehen lassen; seine Latschen wegwerfen; die Latschen hinstellen; die Pantoffeln abgeben. En español: colgar los tenis.

1.4. MORIR ES DEJAR DE LEER EL PERIÓDICO/DE VER LA TELEVISIÓN. En alemán: die/seine Zeitung abstellen; die FAZ/das Handelblatt/den Heideboten/das ND/das Neue Deutschland abbestellen; kein Westfernsehen mehr sehen. En español: quedarle a alg. dos/tres telediarios.

1.5. MORIR ES DEJAR DE COMPRAR. En alemán: jmd. kann nicht mehr im Kaufhof/bei Karstadt/bei Aldi einkaufen; jmd. geht nicht mehr bei Karstadt einkaufen; jmd. kauft nicht mehr bei Horten/Neckermann/C\&A/Leffers ein; jmd. kauft nicht mehr in der Kaufhalle ein; jmd. darf nicht mehr beim Wertkauf einkaufen; beim Konsum gekündigt haben; aus dem Konsum ausgetreten sein; sich beim Konsum abgemeldet haben; nicht mehr im Konsum einkaufen. En español: dejar de comprar tabaco.

${ }^{19}$ Los FR el cortijo de los callados; el cortijo de los silenciosos; el barrio de los "callaos" tienen como objeto referente 'cementerio'. Al igual que el callar funciona como motivación metonímica para designar el acto de morir, a su vez la tumba, elemento constitutivo del frame ENTERRAMIENTO, sirve de dominio fuente para la formación de metáforas con dominio meta 'callar': al. verschwiegen wie ein Grab / esp. (callado) como una tumba (cfr. también al. still wie ein Toter / esp. como un muerto: 'muy callado'). De esta manera comprobamos que la proyección metafórica no funciona en sentido único, sino que es bidireccional. Así, CALLAR es al mismo tiempo dominio fuente y meta de MORIR.

${ }^{20}$ A este FR le subyace, junto a la metonimia causa-efecto, la metáfora LA VIDA ES UN TEATRO (para el alemán cfr. PIIRAINEN 2002: 232): al. von der Bühne abtreten; der Vorhang des Lebens geht herunter / esp. cerrarse el telón; acabarse la función. 
1.6. MORIR ES DEJAR DE PAGAR IMPUESTOS. En alemán: jmd. zahlt keine Steuern mehr; jmd. kann die Steuern nicht mehr bezahlen; jmd. braucht keine Steuern mehr zu zahlen. En español: no pagar más impuestos.

\section{MORIR ES EXPERIMENTAR UNA REACCIÓN CORPORAL ${ }^{21}$}

2.1. REACCIONES DE LAS EXTREMIDADES (en alusión al rigor mortis). En alemán: alle viere von sich strecken; jmd. hat alle viere hochgeklappt; jmd. hat die Füße ausgestreckt; jmd. hat die Hacken/Beine hochgeklappt; die Beine gen Himmel strecken ${ }^{22}$. En español: estirar la pata; torcer/doblar el pescuezo; torcer la pestaña; doblar el gorro; quedarse tieso; estar más tieso que una mojama; estar con la pata tiesa; quedarse más tieso que el ojo de un tuerto; quedarse frito; quedarse fiambre; estar (hecho un) fiambre; hincar el pico; quedarse seco ${ }^{23}$.

2.2. REACCIONES EN EL APARATO EXCRETOR. Solo en alemán: einen kalten Arsch kriegen; sich einen kalten Arsch holen; die (ewige)/eine Grätsche machen; den Hintern/Po zukneifen; den Arsch zumachen; die Arschbacken zukneifen; jmdm. ist das Arschloch zugeschnappt; jmd. hat den Arsch hochgemacht/ hochgerissen; seinen Arsch als Fahrradständer benutzen; jmds. Arsch hat Feierabend; seinen letzten Furz/sein letztes Fürzchen gemacht/gelassen haben; den letzten Scheiß gelassen haben; seinen letzten Köttel kacken; seinen letzten Dreck geschissen haben; den letzten Schiss tun.

2.3. REACCIONES RESPIRATORIAS. Dentro de este grupo aparecen también eufemismos relacionados con la idea extendida desde la Antigüedad de que el alma se expiraba al morir (vid. supra y Profantová 2006). En alemán: seinen letzten Schnaufer machen; seinen letzten Atemzug / die letzten Atemzüge machen; den letzten Seufzer tun; sein letztes Seufzerchen gemacht haben; sein letztes Lüftchen ausgehaucht haben; den letzten Schnapper/Keucher/Japser getan haben; den letzten Atem tun; sein letztes Lüftchen ausgehaucht haben; den letzten Zug tun; sein Leben aushauchen; jmd. hat vergessen, Luft zu holen; jmdm. wird bald die Luft ausgehen; den Odem aushauchen; jmdm. hat aufgehört zu schnaufen. En español, como eufemismos: dar/exhalar el postrer aliento; dar/exhalar el último alien-

${ }^{21}$ En español se tematiza dentro de esta metonimia disfemística también la calvicia: Dentro de cien años todos calvos; el barrio de los calvos (en alusión al 'cementerio').

${ }^{22}$ Inspirados en el mundo animal equino, sin correspondencia en español, son los FR: die Hufe hochmachen/ hochklappen/ hochnehmen/ (hoch)schlagen/ hochreißen/ hochschmeißen/ hochlegen/ (lang)strecken; den Huf an die Decke knallen; die Hufe an die Decke geschlagen haben. De la mano de este grupo de expresiones, así como del FR español estirar la pata, comprobamos el fuerte vínculo entre metáfora y metonimia, ya que a todas ellas les subyace, junto a la mencionada metonimia, la metáfora conceptual LAS PERSONAS SON ANIMALES (cfr. PENADÉS MARTínEZ 2012: 226-233 para la interacción entre metáfora y metonimia en las locuciones idiomáticas).

${ }^{23}$ Como recuerda RodRíguez PONCE (2005: 255), [1]a pérdida de materia líquida o humedad se halla íntimamente relacionada con el cuarto modelo icónico de la delgadez (muerte), en concreto con la archimetáfora DELGADEZ ES SEQUEDAD. A este respecto cfr. el FR quedarse como un pajarito ('morir'), en el que la delgadez interacciona con la muerte. Por su parte, la delgadez y la muerte están íntimamente relacionadas con el campo conceptual de la enfermedad, y comparten con él varios dominios fuente, como p.ej. PUNTO FINAL. Así, el FR esp. estar en las últimas/al. am Ende sein comparten los significados 'estar enfermo' y 'estar próximo a morir' (MELLADO BLANCO 2010: 23-24). 
to/suspiro; dar la última boqueada/bocanada; dar las últimas bocanadas de vida; dar boqueadas. Disfemismos: no resollar más; echar el último resuello.

2.4. REACCIÓN DE LOS OJOS. En alemán: die Augen (auf links) verdrehen; die Augen ausmachen; die Augen zudrücken; die Fensterchen sind zugegangen; die Augen für immer schließen; die Augen auf Null stellen. En español: cerrar la pestaña; cerrar los ojos para siempre; tornar los ojos; poner los ojos en blanco

2.5. MORIR ES DEJAR DE TENER DOLOR FÍSICO O MORAL. En alemán: jmd. hat keine Schmerzen mehr; jmdm. tut nichts mehr weh; jmd. spürt kein Leid mehr; jmdm. tut nie wieder etwas weh; jmdn. stört nichts mehr; jmdm. tun die Zähne nicht mehr weh; jmd. hat keine Zahnschmerzen mehr; jmdm. tut der Kopf nicht mehr weh; jmdm. tut kein Knochen mehr weh; jmdm. juckt/kratzt jetzt nichts mehr; jmdn. regt nichts mehr auf; jmd. hat für ewig ausgesorgt; keine Sorgen mehr haben; aller Sorgen ledig sein. En español: ya no sufrir más; acabársele el sufrimiento a alg.; dejar de sufrir.

\subsection{Motivación metafórica basada en marcos o frames}

Se trata de expresiones metafóricas que se apoyan en un saber extralingüístico (Dobrovol'skij/Piirainen 2009: 24-27), por lo que son más elaboradas que las conceptuales. No se basan directamente en la experiencia del hombre con su entorno, sino en conocimientos extralingüísticos aprendidos. En nuestro corpus destaca el frame o escenario ENTERRAMIENTO ${ }^{24}$, que dan pie a las siguientes archimetáforas:

1. MORIR ES IRSE A LA TUMBA/BAJO TIERRA. Disfemismos en alemán: jmd. hat die Kiste bestiegen; jmd. hat sich in die Kiste gelegt; in der Kiste landen; jmd. ist in die Kiste gegangen/gefahren/gehüpft; jmd. ist in die Kühle gesprungen; ins Kistlein hupfen; in die Grube hüpfen/fahren; in die Gruft steigen/fahren; sich ins Grab legen; unter die Erde gehen; zu den Würmern gehen; jmd. ist umgezogen; jmd. ist ein Stockwerk/eine Etage tiefer gezogen; in den Kasten springen/gehen; jmd. ist in den Sarg gekrochen; den Holzpyjama anziehen. En español: irse al hoyo; acabar en el hoyo; ponerse el pijama de palo/de madera; irse a la tumba; hacerse un traje de pino.

2. ESTAR MUERTO ES ESTAR EN EL ATAÚD. En alemán: jmd. liegt in der Kiste und bekommt kalte Füße; jmd. winkt schon aus dem Sarg; Kisten-Party haben; ein Nickerchen in der Kiste machen; den Deckel/Sargdeckel von innen zumachen; den Deckel (hinter sich) geschlossen/zugemacht haben; jmd. hat aufs Brett geschissen; jmd. hat den Deckel schon in der Hand; jmdm. guckt schon der Sargdeckel aus dem Gesicht; jmd. hat der Sargdeckel schon ins Gesicht geschlagen; den Deckel auf der Nase haben; jmd. hat schon lange einen Deckel auf der Nase;

${ }^{24}$ El rito del entierro de los fallecidos es un elemento fundamental acerca de la muerte en nuestra cultura, por lo cual el escenario del ENTERRAMIENTO permite comprender la motivación de muchas metáforas del alemán y el español. No podemos, sin embargo, descartar otras culturas en las que los muertos no se entierren, para cuyos hablantes nuestras metáforas no serían transparentes por tratarse de un conocimiento aprendido en el proceso de la vida. 
sich ein Bett mit Deckel gekauft haben; jmd. kann schon mal die Bretter nageln; $j m d$. hat schon Bretter auf dem Buckel; jmd. hat seine sechs Bretter schon zusammen; mit den Füßen zuerst rausgetragen/hinausgetragen werden; den Holzpyjama anhaben; im Holzpyjama liegen. En español: estar en la caja (de pino); sacar a alg. con los pies por delante; salir con los pies por delante; oler el barniz de la caja; estar con el traje de pino.

3. ESTAR MUERTO ES ESTAR DEBAJO DE LA TIERRA. En alemán: jetzt liegt jmd. einen Meter tiefer; unter der Erde liegen; 1'80 m unter der Grasnarbe liegen; drei Meter Erde überm Bauch haben; jmd. ist jetzt zwei Fuß unter der Erde; drei Fu $\beta$ tief ruhen; man hat jmdn. sechs Fu $\beta$ tiefer gelegt; jmd. hat jetzt eine Kellerwohnung; sich mit Erde vertraut machen; jmd. riecht schon nach Erde; jmd. kaut schon Erde/Müll; die Blümlein von unten anschauen; sich die Radieschen von unten anschauen. En español: estar a dos metros bajo tierra; estar en el hoyo; tener encima siete pies de tierra; comer/mascar tierra; estar bajo tierra; ver crecer las flores desde abajo; ver (crecer) las margaritas desde abajo.

4. ESTAR MUERTO ES SER ABONO DE PLANTAS. En alemán: jmd. bekommt jetzt Besuch mit der Gießkanne; jmd. hat (jetzt) einen Garten/ein Gärtlein auf dem Bauch; beim Pastor im Garten liegen; die Blumen düngen. En español: estar (ya) criando malvas/lilas; criar gurumelos/jaramagos; irse pal'jardín; quedar para simiente de rábanos; el patio de las malvas; tener ya un jaramago.

5. ESTAR EN MUERTO ES ESTAR CON TOPOS Y GUSANOS. Solo en alemán: den Maulwürfen/den Würmern Gesellschaft leisten; den Maulwürfen guten Tag sagen; bei den Würmern liegen; die Würmer grüßen; jmd. tanzt jetzt mit den Regenswürmern; mit den Würmern Karten spielen.

6. ESTAR MUERTO ES SER COMIDA DE GUSANOS. En alemán: jmd. füttert jetzt die Regenswürmer; jmd. ist jetzt Wurmfutter; von den Würmern zerfressen werden; an jmdm. schmatzen die Würmer; die Würmer haben sich schon die Serviette umgebunden. En español: dar de comer a los gusanos; ser pasto de (los) gusanos; pudrirse con/como los gusanos; quedar para comida de gusanos; comérselo a alg. los gusanos.

\subsection{Motivación simbólica}

Al margen de la motivación metafórica y por metonimia, en los eufemismos y disfemismos del campo conceptual MUERTE/TOD se revela un importante tipo de motivación que es la simbólica, de raíces culturales y relacionada con creencias religiosas, con costumbres funerarias o en general con el imaginario de un pueblo. Ciertamente, en la motivación simbólica se hace evidente una fuerte presencia de la religión, ya que la creencia en una continuidad de la vida después de la muerte o la idea de un paraíso donde todas las buenas almas llegan, hacen que el hablante utilice de manera habitual esas expresiones a manera de consuelo y negación de la muerte como fin de la vida humana.

La motivación simbólica raras veces aparece en estado puro, combinándose casi siempre con las distintas formas de la motivación metafórica. No es objeto de este trabajo abordar la compleja cuestión de la imbrincación de ambos tipos de motiva- 
ción o decidir si domina una sobre la otra en las distintas expresiones (para los "widespread idioms" en Europa y Asia cfr. Piirainen 2012). Interesante es, en todo caso, la superposición del nivel de metáforas conceptuales con el nivel simbólico, condicionado en el caso del español y el alemán de manera extrema por el Cristianismo y las creencias religosas en torno a la muerte ${ }^{25}$. Tanto en alemán como en español observamos las siguientes superposiciones de tipo de motivación:

1. Motivación metafórica (metáfora conceptual MORIR ES DESCANSAR) + motivación simbólica (religión cristiana). En español: descansar en el seno de Abraham; descansar en la gloria/paz del Señor; descansar en paz; descansar en el Señor/en el cielo; el descanso eterno; dejar a los muertos descansar/en paz. En alemán: im Abrahams Schoss sein; in Gottes Erdboden ruhen; in Gott ruhen; die ewige Ruhe finden; sanft und selig entschlafen; die Toten soll man (in Frieden) ruhen lassen.

2. Motivación metafórica (metáfora conceptual MORIR ES MARCHARSE) + motivación simbólica (religión cristiana). En español: irse/subir al cielo; pasar a mejor vida. En alemán: zu Gott gerufen werden; zum lieben Gott gegangen sein; vor den Schöpfer treten.

3. Motivación metafórica (metáfora conceptual MORIR ES FINALIZAR UN CAMINO) + motivación simbólica (religión cristiana). En español: camino hacia Dios; camino a/hacia la gloria; el camino que todos hemos de recorrer. En alemán: den Weg allen Fleisches/alles Irdischen gehen; den Weg gehen, den wir alle gehen müssen.

De los estudios que tratan la metáfora conceptual LA VIDA ES UN CAMINO (vid. supra 3.1.A) (Jäkel 2003: 261-283; Baldauf 1997), se desprende que el esquema de imagen del CAMINO da lugar a metáforas ontológicas de base conceptual, relacionadas con el paso del tiempo y el final de la vida, pero también a otras muchas de carácter más simbólico y base cultural. Estas últimas, en gran número en la Biblia, descansan en las dicotomías camino bueno vs. camino malo; camino recto vs. camino torcido; camino llano vs. camino obstaculizado; camino de luz vs. camino oscuro; camino eterno vs. camino de muerte. Asimismo, el camino de Dios, que aparece en singular, es el buen camino, al que se oponen, en plural, los caminos del mal, los caminos del diablo que están torcidos, oscuros y llenos de obstáculos (cfr. Mellado Blanco 2009). Las siguientes metáforas basadas en el esquema de imagen CAMINO tienen un fuerte componente simbólico-religioso:

\footnotetext{
${ }^{25}$ El sustrato simbólico-cultural, específico de cada comunidad lingüística, también puede estar relacionado con otro tipo de saber más general, no necesariamente con el de la religión, sino simplemente con un conocimiento básico acerca del mundo que nos rodea, lo que DoBROVOL'SKIJ/PIIRAINEN (1997: 116) denominan "Etalon-Wissen". Para ilustrar esto, los autores ponen como ejemplo el FR den Löffel abgeben, al que le subyace la metáfora LEBEN IST ESSEN, pero que también revela una motivación simbólica relacionada con el citado "Etalon-Wissen", puesto que "Löffel das prototypische Instrument zum Essen darstellt (nicht Gabel und Messer)".
} 
1. MORIR ES ATRAVESAR UN UMBRAL ${ }^{26}$. En alemán: über die Wupper gehen/springen; über den Deister gehen; über den Harz sein; in den Hafen einlaufen; über Bord gehen; hinüber gleiten/sein; die Seite wechseln; in eine andere Welt gehen; ans andere Ufer gehen; ins Jenseits abberufen werden; ins Jenseits eintauchen. En español: estar más "pallá" que "pacá"; irse/pasar al otro barrio; irse al otro mundo; estar con un pie en ultratumba; ir al más allá.

2. MORIR ES ES IR A UN MUNDO MEJOR/ETERNO; MORIR ES IR AL CIELO. En alemán: in eine bessere Welt gehen; in die Glückseligkeit eingehen; heim in die Ewigkeit gehen; in die Ewigkeit abberufen werden; himmelan gehen; in den Himmel aufgefahren sein; gen Himmel schweben. En español: ir(se) al cielo; subir al cielo/a los cielos; irse a un mundo mejor; ir a la eternidad; pasar a mejor vida; volar al cielo; irse de/abandonar este valle de lágrimas.

3. ESTAR MUERTO ES ESTAR ARRIBA ${ }^{27}$. En alemán: sich alles von oben angucken; die Welt von oben besehen; jmd. schaut uns von oben zu; die Sterne von oben sehen. En español: estar (alli) arriba; estar con las estrellas; estar con los angelitos.

4. MORIR ES ENCONTRARSE CON DIOS/SER LLAMADO POR DIOS. En alemán: zu Gott gerufen werden ${ }^{28}$; vor den/seinen Schöpfer treten; zum lieben Gott gegangen sein; seinem Schöpfer entgegentreten; zu seinem Schöpfer abberufen werden; jmd. schaut den Schöpfer nun von Angesicht zu Angesicht; vom Herrn heimgerufen werden; dem Herrgott ins Angesicht schauen; vor seinen Herrn und Richter treten; zu seinem Herrn gefahren sein; dem großen Geist begegnen. En español: acoger Dios a alg. en su seno; Dios se ha acordado de alg.; llamar Dios a alg. (a su lado/vera); llevarse Dios a alg.; reunirse con el Creador.

5. MORIR ES ENCONTRARSE CON PERSONAJES BÍBLICOS EN EL CIELO $^{29}$. En alemán: Petrus hat jmdn. zu sich genommen; bei Petrus sein; bei Petrus an die Tür klopfen; bald an die Himmelspforte klopfen; an die Himmelstür geklopft haben; zu den Engeln gehen; jmd. singt jetzt mit den Engeln (im Himmelschor); jmd. spielt nun bei den Engeln auf Harfen; die Engel haben jmdn. schon angelächelt; sich den himmlischen Heerscharen angeschlossen haben. En español: ser recibido por San Pedro; llamar a la puerta de San Pedro; llamar a las puertas del cielo; irse con los angelitos; estar con los ángeles del cielo; estar en compañía de los ángeles del cielo.

\footnotetext{
${ }^{26}$ En los FR alemanes nach Walhalla gehen; in den Orkus fahren; in den Hades gehen; ins Nirwana gehen/kommen/eingehen; zum großen Manitu gehen, se encuentra motivación simbólica basada en otras creencias religiosas diferentes a la cristiana (PIIRAINEN 2002: 234).

${ }^{27}$ Basada en la metáfora orientacional LO BUENO ES ARRIBA (LAKOFF/JOHNSON 1986: 53).

${ }^{28}$ Las siguientes expresiones tienen una variante disfemística en alemán: bei Elvis im Chor singen; vor Elvis sein/treten; Elvis hat jmdn. zu sich gerufen; in die große Armee abberufen werden.

${ }^{29}$ En algunos casos aparecen otras deidades diferentes al Dios cristiano: an Odins Tafel sitzen; er ist in Manitus Reich; er ist beim großen Manitu. A excepción de los FR relacionados con la mitología helénica (p. ej. entrar en el reino del Hades o ir a estar con el barquero), los elementos de religiones diferentes a la cristiana no forman parte del imaginario fraseológico del español.
} 
6. MORIR ES REENCONTRARSE CON LOS ANTEPASADOS. En alemán: $z u$ den Vätern/Großvätern/Altvorderen/Anderen gehen; sich zu seinen Ahnen/Vätern versammelt haben; zu den Vorvätern eingegangen sein; zu den Ahnen abgerufen sein; zu seinen Ahnen abreiten. En español: (ir a) reunirse con sus seres queridos; (ir a) reunirse con sus antepasados; reencontrarse con sus seres queridos.

\section{Balance final}

El trance de 'morir' se verbaliza en español y alemán por medio de eufemismos y disfemismos que designan el objeto denotado de manera indirecta. Teniendo en este estudio como marco la lingüística cognitiva, se observan disfemismos sobre todo en los modelos conceptuales de base metonímica MORIR ES DEJAR DE HACER UNA ACTIVIDAD COTIDIANA; MORIR ES EXPERIMENTAR UNA REACCIÓN CORPORAL, en los que el hablante recurre a imágenes irreverentes, escatológicas y cargadas de ironía para enfrentarse con humor realista al tabú de la muerte. Los eufemismos, por el contrario, son más frecuentes en las expresiones de motivación simbólica, tratándose en su mayoría de metáforas asociadas a elementos procedentes de la religión cristiana, cuyo objetivo es minimizar el impacto de la muerte negándola con la promesa de una vida eterna y un nuevo camino por recorrer. Por su parte, el frame ENTERRAMIENTO, a menudo mediante el slot ATAÚD, es fuente importante de metáforas paralelas en alemán y español. Se trata aquí de disfemismos dotados de elevada dosis de realismo, a veces trágico, que aluden sin rodeos a la desintegración de la materia corporal.

Lo expuesto con anterioridad nos lleva, por tanto, a conjeturar importantes concomitancias interlingüísticas e interculturales entre el alemán y el español. Ambas lenguas explotan recursos afines basados en modelos metonímicos básicos (MORIR ES DEJAR DE HACER UNA ACTIVIDAD COTIDIANA; MORIR ES EXPERIMENTAR UNA REACCIÓN CORPORAL) y en archimetáforas paralelas (MORIR ES DESCANSAR; MORIR ES MARCHARSE, etc.). En los modelos cognitivos se entrecruza lo metafórico con lo simbólico, representado en campo conceptual MUERTE/TOD a través de creencias derivadas de la religión cristiana. Si bien puede suceder que las expresiones de una lengua no tengan un equivalente pleno en la otra, lo llamativo es que a la mayoría de las unidades analizadas les subyacen idénticas metáforas o metonimias, después de recorrer similares procesos de motivación. En este sentido, coincidimos con la apreciación de Wotjak (1988: 480) de que las convergencias interlingüísticas se dan con mucha mayor frecuencia en el nivel semántico funcional (significado fraseológico) que en el nivel formal o en las imágenes concretas que actualizan cada archimetáfora. Así por ejemplo, en ambas lenguas existe el modelo cognitivo MORIR ES DEJAR DE HACER UNA ACTIVIDAD COTIDIANA y dentro de él la archimetáfora MORIR ES DEJAR DE HABLAR, pero las imágenes con esta invariable semántica no tienen que ser idénticas en ambas lenguas. De esta manera, el FR español (ya) no contarla no tiene isomorfia (ni total ni figurativa) en alemán, encontrándose en esta lengua FR que 
responden a la misma archimetáfora (p. ej. al. keinen Piep mehr sagen/machen/tun), pero no en la misma forma ni con la misma imagen concreta $(* e s$ nicht mehr erzählen). En otras ocasiones, la imagen perteneciente a un modelo cognitivo común revela un alto grado de paralelismo, sin llegar a ser idéntica, como sucede con el FR español colgar los tenis, con imagen comparable pero no exactamente igual en el alemán: die Schuhe stehen lassen; seine Latschen wegwerfen/hinstellen; die Pantoffeln abgeben.

Asimismo, el importante modelo cognitivo MORIR ES EXPERIMENTAR UNA REACCIÓN CORPORAL, muy productivo tanto en alemán como en español, alberga en alemán ciertos disfemismos cuya imagen escatológica ("reacciones del aparato excretor") no tiene parangón en español, p. ej. einen kalten Arsch kriegen; sich einen kalten Arsch holen; den Arsch zukneifen. Los datos recopilados y analizados en este trabajo parecen apuntar a una mayor secularización de la muerte y a una pérdida de su dimensión metafísica en el caso de la comunidad alemana, sobre todo si consideramos el elevado número de neologismos disfemísticos basados en imágenes irreverentes o ridículas del moribundo (expresiones tomadas en su mayoría de Piirainen, 2002) ${ }^{30}$.

Por último, dentro de archimetáforas coincidentes en ambas lenguas, como MORIR ES MARCHARSE/EMPRENDER UN VIAJE, la presencia de elementos simbólicos puede llegar a ser la causante de asimetrías interlingüísticas. Este sería el caso de los FR alemanes relacionados con la religión amerindia, como in die ewigen Jagdgründe eingehen/ziehen/verschwinden; ins Reich der ewigen Jagdgründe gehen, difundidos en Alemania gracias a la gran popularidad de los relatos de Karl May (Piirainen 2002: 234).

\section{Referencias bibliográficas}

\section{Diccionarios consultados}

Balzer, B. / Moreno, C. / Piñel, R. / Raders, M. / Schilling, M. ${ }^{a}$ L., Kein Blatt vor den Mund nehmen. No tener pelos en la lengua. Diccionario fraseológico alemánespañol. Madrid: Editorial Idiomas, Hueber 2010.

BeINHAUER, W., Stilistisch-phraseologisches Wörterbuch Spanisch-Deutsch. Múnich: Hueber 1978.

Buitrago, A., Diccionario de dichos y frases hechas. Madrid: Espasa Calpe 2002.

CANTERA, J., Diccionario de fraseología española: locuciones, idiotismos, modismos y frases hechas usuales en español. Madrid: Abada 2007.

Real ACAdemia Española, Diccionario de la lengua española $\left(22^{\mathrm{a}}\right.$ ed.), 2001. http://www.drae.rae.es. [24/04/2013].

DudEn, Deutsches Universalwörterbuch. Mannheim: Dudenverlag 1989.

\footnotetext{
${ }^{30}$ No obstante, el hecho de que el corpus de expresiones no lematizadas en alemán sea superior al del español no permite extraer conclusiones concluyentes en este sentido, quedando abierta la posibilidad de que un corpus de locuciones no lexicalizadas más completo en español arrojara un mayor volumen de expresiones disfemísticas en esta lengua.
} 
DuDEN, Redewendungen. Wörterbuch der deutschen Idiomatik. vol. 11. Mannheim: Dudenverlag 2002.

GLÜCK, H. (ed.), Metzler Lexikon Sprache. Stuttgart: Metzler 1993.

HESSKY, R./ETTINGER, S., Deutsche Redewendungen. Ein Wörter- und Übungsbuch für Fortgeschrittene. Tubinga: Gunter Narr 1977.

IRIBARREN, J. M., El porqué de los dichos. Pamplona: Gobierno de Navarra 1994.

LAROUSSE Gran Diccionario de Frases Hechas. Barcelona: Larousse 2001.

Moliner, M., Diccionario de uso del español. Madrid: Gredos ( $3^{\mathrm{a}}$ ed.) 2007.

Nedwed, S. / Romeu Nedwed, C., Diccionario fraseológico. Español y alemán. Barcelona: Ediciones del Serbal 2009.

RoDríGUEZ-VIDA, S., Diccionario temático de frases hechas. Barcelona: Octaedro 2011.

RÖHRICH, L., Lexikon der sprichwörtlichen Redensarten. Friburgo: Herder 2004.

Schemann, H., Deutsche Idiomatik. Wörterbuch der deutschen Redewendungen im Kontext. Berlín: de Gruyter 2011.

SchemanN, H., Synonymwörterbuch der deutschen Redensarten. Berlín: de Gruyter 2012.

Schemann, H. / Mellado, C. / Buján, P. / Iglesias, N. / Larreta, J. P. / Mansilla, A., Idiomatik Deutsch-Spanisch. Hamburgo: Buske 2013.

SECO, M. (dir.), Diccionario fraseológico documentado del español actual: locuciones y modismos españoles. Madrid: Aguilar 2004.

\section{Bibliografía secundaria}

ANDERS, H., Never say die: englische Idiome um den Tod und das Sterben. Berlín: Peter Lang 1995.

Baldauf, C., Metapher und Kognition. Grundlagen einer neuen Theorie der Alltagsmetapher. Berlín: Peter Lang 1997.

Baranov, A. / Dobrovol'skiJ, D., Aspectos teóricos da fraseoloxía. Santiago de Compostela: Xunta de Galicia 2009.

BiELiŃSKA, M., Verben des Sterbens und des Tötens. Berlín: Peter Lang 2002.

BIERICH, A., "The semantich field "death" in czech, russian, croatian and serbian phraseologie», en: DuRČO, P. (ed.), Europhras '97: Phraseology and Paremiology (International Symposium, September 2-5, 1997, Liptovský Ján). Bratislava: Akadémia PZ 1998, 17-23.

BujÁN OTERO, P., «Pataqueiras e Radieschen: fraseoloxía da morte en alemán e galego», Cadernos de Fraseoloxía Galega 14 (2012), 83-98.

Buján Otero, P. / Mellado Blanco, C., «Dormir el sueño de los justos. Fraseología y valores pragmáticos a partir de corpus textuales en alemán y español», en: MosKOWICH-SPIEGEL FANDIÑO, I. et al. (eds.), Language Windowing through Corpora. A Coruña: Universidade da Coruña 2010, 125-137.

Bultnick, B., Metaphors we die by: Conceptualizations of Death in English and their implications for the theory of the metaphor. Amberes: Universidad de Amberes 1998.

Burger, H., Phraseologie. Eine Einführung am Beispiel des Deutschen. Berlín: Erich Schmidt 2010.

CASARES, J., Introducción a la lexicografía moderna. Madrid: CSIC 1992.

Chamizo Domínguez, P. J., «La función social y cognitiva del eufemismo y del disfemismo»,Panace@ V/15 (2004), 45-51.

Chamizo Domínguez, P. J. / SÁnchez Benedito, F., Lo que nunca se aprendió en clase. Eufemismos y disfemismos en el lenguaje erótico inglés. Granada: Comares 2000. 
CRESPO FERNÁNDEZ, E., «La conceptualización metafórica del eufemismo en epitafios», Estudios Filológicos 43 (2008), 83-100.

Dobrovol'skit, D. / PiIRAINEN, E., Symbole in Sprache und Kultur: Studien zur Phraseologie aus kultursemiotischer Perspektive. Bochum: Brockmeyer 1997.

Dobrovol'SkiJ, D. /PIIRAINEN, E., Zur Theorie der Phraseologie. Kognitive und kulturelle Aspekte. Tubinga: Stauffenburg 2009.

Fructuoso, J., «Breve historia del alma en la Antigüedad», Tonos. Revista Electrónica de Estudios Filológicos XII diciembre (2006). http://www.tonosdigital.es/ojs/index.php/tonos/article/view/65/63. [24/04/2013].

Hessky, R., «Das euphemistische Idiom - eine Problemskizze», en: HäCKI BuHOFER, A. et al. (ed.), Phraseologiae Amor. Aspekte europäischer Phraseologie. Baltmannsweiler: Schneider 2001, 163-175.

IÑESTA MENA, E. M. / PAMIES BeRTRÁN, A., Fraseología y metáfora: aspectos tipológicos y cognitivos. Granada: Granada Lingvistica 2002.

JACHNOW, H., «Der Tod und die Sprache. Beobachtungen zu sprachlichen Ersatzstrategien mit Hilfe von Phraseologismen und Stereotypen bei der Kommunikation über Sterben und Tod», Slavistische Linguistik. Múnich: Otto Sagner 1995, 175-195.

JÄKEL, O., Wie Metaphern Wissen schaffen. Die kognitive Metapherntheorie und ihre Anwendung in Modell-Analysen der Discursbereiche Geistestätigkeit, Wirtschaft, Wissenschaft und Religion. Hamburgo: Dr. Kovač 2003.

LAKoff, G., Women, Fire, and Dangerous Things. What Categories Reveal about the Mind. Chicago/Londres: The Chicago University Press 1987.

LAKoff, G. / Johnson, M., Metáforas de la vida cotidiana. Madrid: Cátedra 1986.

Luchtenberg, S., Euphemismen im heutigen Deutsch. Berlín: Peter Lang 1985.

MANSILlA PÉREZ, A., «La ordenación onomasiológica del material fraseológico», en: Mellado Blanco, C. et al. (eds.), La fraseografia del S. XXI. Nuevas propuestas para el español y el alemán. Berlín: Frank \& Timme 2010, 27-36.

MARÍn-ARReSE, J. I., «To die, to sleep. A contrastive study of metaphors for death and dying in english and spanish», Language Sciences 18 (1996), 37-52.

Mellado Blanco, C. (ed.), Theorie und Praxis der idiomatischen Wörterbücher (Lexicographica Series Maior, 135). Berlín: de Gruyter 2009.

MELLADO BLANCO, C., «Introducción y planteamiento del proyecto. Los modelos cognitivos», en: Mellado Blanco, C. et al. (eds.), La fraseografia del S. XXI. Nuevas propuestas para el español y el alemán. Berlín: Frank \& Timme 2010, 17-25.

Mellado Blanco, C. / Iglesias Iglesias, N., «Significado y análisis de corpus en la fraseografía bilingüe español-alemán», en: RoIss, S. et al. (eds.), En las vertientes de la traducción e interpretación del/al alemán. Berlín: Frank \& Timme 2011, 119-133.

Mellado Blanco, C., Kontrastive Phraseologie Deutsch-Spanisch. Semantische Aspekte. Tubinga: Julius Groos 2013.

Penadés Martínez, I., Gramática y semántica de las locuciones. Alcalá de Henares: UAH 2012.

PIIRAINEN, E., Phraseologie der westmüsterländischen Mundart. Semantische, kulturelle und pragmatische Aspekte dialektaler Phraseologismen. Baltmannsweiler: Schneider 2000.

PIIRAINEN, E., «Er zahlt keine Steuern mehr. Phraseologismen für 'sterben' in den deutschen Umgangssprachen», en: PIIRAINEN, E. / PIIRAINEN, I. T. (ed.), Phraseologie in Raum und Zeit. Baltmannsweiler: Schneider 2002, 213-238. 
PIIRAINEN, E., Widespread Idioms in Europe and Beyond. Toward a Lexicon of Common Figurative Units. Nueva York: Peter Lang 2012.

PIÑEL LÓPEZ, R. M., «Der Tod und das Sterben in der deutschen und spanischen Phraseologie: ein interkultureller Vergleich», en BURGER, H. et al. (ed.), Flut von Texten Vielfalt der Kulturen. Baltmannsweiler: Schneider 2003, 229-238.

ProfantovÁ, Z., «Plurima mortes imago», Studia Mythologica Slavica IX (2006), 299320.

REUTNER, U., Sprache und Tabu: Interpretationen zu französischen und italienischen Euphemismen. Tubinga: Niemeyer 2009.

RODRÍGUEZ PONCE, M. I., «La enfermedad en español: enfoque etnolingüístico a través del Diccionario Ideológico de Julio Casares», Anuario de Estudios Filológicos XXVIII (2005), 249-264.

RUIZ GURILLO, L, «La gramaticalización de unidades fraseológicas irónicas», en: RUIZ Gurillo, L. / Padilla García, X. A. (eds.), Dime cómo ironizas y te diré quién eres. Berlín: Peter Lang 2009, 371-390.

SCHEMANN, H., «Wissenschaftliche Einführung: Synonymie und Idiomatik», en: SCHEMANN, H., Synonymwörterbuch der deutschen Redensarten. Berlín: de Gruyter 2012, 13-188.

SEARLE, J. F., An Essay in the philosophy of language. Cambridge: Cambridge University 1969.

WотJAK, G. «Übereinzelsprachiges und Einzelsprachspezifisches bei Phraseolexemen», en: GrÉCIANO, G. (ed.), Europhras 88. Actes du Colloque International KlingenthalStrasbourg. Estrasburgo: Université des Sciences Humaines 1988, 469-483. 